\title{
Material and Particle Analysis - the Microscopical Path
}

\author{
D. Scott Aldrich
}

\section{Ultramikro LLC 11133 East D Avenue, Richland, MI 49083-9318}

The great aspect about working in the pharmaceutical industry is the variety of materials and products we are challenged with understanding, developing and fabricating for sale. Of course, it is just these aspects that cause us frustration as well, when the best molecule in the most protective package isn't stable or defies use by the consumer or practitioner. Also prevalent are changes in our products initiated by suppliers' changes/improvements and effects from equipment contact, leaching and storage or physical environment. Not only are we called upon to analyze the product components, but also any substance or condition that arise to foil our best efforts for production.

Analysis of product components, production equipment materials and separated particles is facilitated by a great number of microscopical instruments and related tools. While the common desire is to attain full analysis in a single instrumental approach, it is rarely possible. Analytical microscopy is greatly benefitted by specialized tools, methods, and common sense approaches for separation, categorization and identification.

The presentation will review the microscopical analytical approach, a systematic methodology starting with the simplest tests and observations, to selected methods for confirmation of identity. The term ultramicroanalysis is used to describe the examination of ensemble and components of material, in a "Look Early, Look Often" approach.

All particle sources, potential contamination and their pathways must be understood, in order to alleviate their presence. Primary tools in the evaluation of particle isolates are

a) stereomicroscopy as a triage function, Figure 1;

b) applied polarized light microscopy as a screening and identification tool,

c) spectroscopy, especially infrared, for molecular identification ${ }^{1}$, and

d) scanning electron microscopy with elemental analysis (SEM-EDX) to provide supplemental particle character and elemental composition.

Optical microscopy applications allow size, shape color, crystallinity, solubility, thermal behavior and optical axis quantitation. Spectroscopical interrogation of the unknown, especially infrared micro-spectroscopy will provide molecular character if not identity, preserving the sample. Electron microscopy provides highly resolved imaging and elemental content without sample destruction.

The analytical approach is coordinated through selection of tools and procedures as deemed necessary through the microscopical observations of pharmaceutical sample characteristics. Additionally, visual inspection methods for liquid products, when used with experienced personnel in conjunction with microscopical evaluation of the particles, yield a comprehensive identification, location of cause(s) and ultimately, formulation improvement. 
Applied polarized microscopy means direct and singular analysis of each particle category found in the product batch, using the principles of chemical microscopy. Just as it is important to count and size the particle population, elucidating the nature of the particulate matter behind the numbers will lead to robust formulations and stable final product forms. Examples of two general categories of particles will be discussed and demonstrated; extrinsic and intrinsic sources. Discussion of the important contamination pathways will be included; active ingredient salt forms, degradation, oligamerization, coalescence, impurities, crystallization, and hydrate formation. Also, package and process extracts and degradation will be discussed. ${ }^{2}$

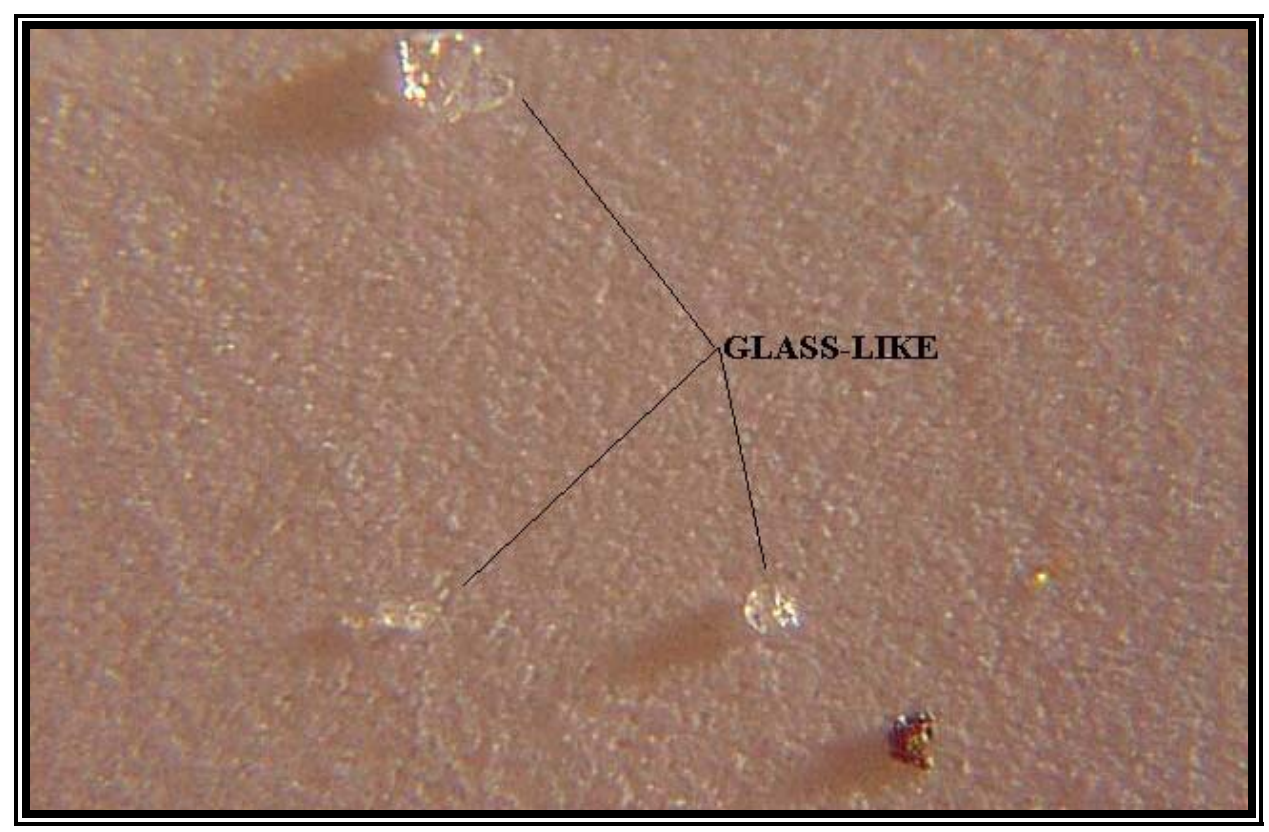

FIG. 1. Isolated particles from a pharmaceutical sterile parenteral formulation on a $0.45 \mu \mathrm{m}$ membrane filter.

\section{REFERENCES}

${ }^{1}$ Aldrich, D.S. and Smith, M.APharmaceutical Applications of Infrared Microspectroscopy, in Humecki, H., Editor, "Practical Guide to Infrared Microspectroscopy", 2nd Edition, 1995 Marcel Dekker, New York, NY. pg. 323375. [reprinted 1999 in Applied Spectroscopy Reviews 34(4)275-327.]

${ }^{2}$ Aldrich D.S. Particulate Matter: Sub-Visible. Chapter in: Nema S and Ludwig JD, eds. Pharmaceutical Dosage Forms: Parenteral Medications, Third ed., Informa Healthcare, New York, in press. 